\title{
Human-nature relationships in experiential meaning: transitivity system of Chinese from an ecolinguistic perspective
}

\author{
Ruijie Zhang (D) and Wei He ${ }^{b}$

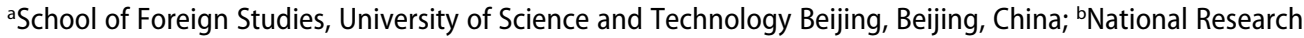 \\ Center of Foreign Language Education, Beijing Foreign Studies University, Beijing, China
}

\begin{abstract}
Following a systemic functional approach to ecolinguistic studies, this study explores the Chinese transitivity system's interpretative potential in revealing the dynamic relationship between human beings and their living places. The research extends the transitivity system under the ethical framework of Ecological Sense of Place, drawing on theories from human geography and traditional Chinese philosophies. Within such a premise, the system of process configurations and participants of Chinese process types are reinterpreted, arguing that both the participant and the process should be judged through an ecological lens concerning their function in construing the human-place relationships. The scale of influence and environmental stances of Participant roles is addressed, following a belief that every entity contains participative potential as -er/ed role of a process. Place as a circumstantial role is expressly acknowledged for their contribution to circumscribe people-place relationships. Regarding the process types, a reconsideration of their emotive, cognitive and agentive features is proposed to reveal the embedded attitudes toward places. These observations extend the knowledge on how the transitivity system can be refined to show the speaker/writer's attitude toward the ecology and its further influences on the collective understanding of human-nature relationships.
\end{abstract}

\section{ARTICLE HISTORY}

Received 8 April 2020

Accepted 30 August 2020

\section{KEYWORDS}

Human-nature relationship; experiential meaning; transitivity system of Chinese; ecolinguistic perspective

\section{Introduction}

In a course taught by a Berkeley professor, when students were asked to identify a sprawling Monterey pine on the campus, none of them could provide an answer. Ironically, this same group of students could converse knowledgeably about chlorofluorocarbon and the ozone hole as a regular environmentalist (Heise 2008, 28). It is not unsurprising to find many people, even environmentalists, talking about ecological issues such as climate change, air pollution or deforestation more often than they talk about the most immediate surrounding environment. This phenomenon embodies a challenge we now face: do we have a chance of changing our relationship to the natural world if we do not know what is around us? 
Humans and nature, or to be more specific, people and their living place, are inextricably linked to each other to create all sorts of living experiences. It is safe to say that place is bound up in people's sources of meaning and experience while people and places are mutually constructed and constituted (Harvey 2001). In this mutual constructing process, the establishment of the self is impossible without the context of place, and "there is no such thing as an individual, only an individual-in-context, individual as a component of place, defined by place" (Evernden 1978, 103). Through the intricate biological and social-cultural processes that take place while people experience (namely by interacting, knowing, perceiving or living) the physical environment (Hausmann et al. 2016), people develop a sense of place that represents perception and interpretation of the environment in an emotional, spiritual and cognitive way (Tuan 1977; Jorgensen and Stedman 2001). Therefore, approaching the people-place relationship is a prerequisite in touching the grand topic of ecology and its most relevant and urgent topic of ecological awareness and activism.

Human beings also exist as social groups, and our social activities give rise to language and exist through language, granting language the power of representing and shaping the world. Sapir (1912) believes that "it is the vocabulary of a language that most clearly reflects the physical and social environment of its speakers." In 1985, French linguist Claude Hagège used the term ecolinguistics (écolinguistique) for the first time to represent the study of linguistic representations of natural phenomena. In 1990, the Halliday approach ${ }^{1}$ to ecolinguistic study was initiated when M.A.K Halliday delivered his keynote speech "New Ways of Meaning: The Challenge to Applied Linguistics" given at AILA IX. Halliday opened up the channel for linguists to care for the environment by asking if linguistic patterns affect the survival and well-being of the human species as well as other species on the Earth (Halliday 1990). Mühlhäusler and Mühlhäusler (2003, 91) similarly claims that "grammatical constructions have developed in the more recent past that might encourage language habits which have contributed to our present environmental crisis." These researches laid the foundations for future endeavors to discuss the grammatical features in our communication and their influences on the ecology.

According to Halliday (1994), language as a semantic system plays the central role in storing, exchanging and construing experience, and it is a semiotic system organized as sets of choices made within three metafunctional meanings: experiential, interpersonal and textual meaning. Among these three metafunctions, the experiential meaning is perhaps the most common understanding of meaning. In this sense, a clause has meaning as processes in ongoing human experience. Choices in experiential meaning help build a sense of the world around us, about what it consists of and how people might engage in it, therefore representating the people-place relationship construed in language. With a primary concern for the ecology, especially the immediate components of people-place relationships, this research will follow the Halliday approach to provide an interpretive framework for revealing the ecological implications embedded in the experiential meaning of language.

This study is expected to provide theoretical inspirations for future eco-oriented studies, especially those of ecological discourse analysis. The end is to help raise general awareness of the most immediate people-place relationships and help construe more ecologically friendly discourses. 


\section{Experiential meaning, transitivity system of Chinese and ecolinguistic studies}

Experiences, the particulars of the world around us and inside our heads, can be interpreted as "a resource, a potential for understanding, representing and acting on reality" (Halliday and Matthiessen 1999, 1). Our most powerful impression of experience is that it consists of a flow of events, or goings-on and the grammatical system by which they are achieved is that of transitivity (Halliday and Matthiessen 2014, 213). In the grammar of clause, a process unfolds through time and contains participants being directly involved in this process, together with the circumstances of time, space, cause, manner, or one of a few other types. Halliday (1994) pictures the transitivity of English with a manageable set of process types, including material, mental, relational, behavioral, verbal and existential processes. For each process, a set of configurations is involved in construing a particular domain of experience. The material process portrays our outer experience, and it is what we experience as going on out there. The mental process, on the contrary, portrays our inner experience in the world of consciousness. The relational process serves to characterize and to identify. The behavioral process represents the outer manifestations of inner workings. The verbal process categorizes human consciousness manifested in the form of language. The existential process includes all kinds of experiences recognized to exist or to happen.

Halliday's categorization of the English transitivity has been widely discussed and applied in many functional studies. Matthiessen (1995) and Halliday and Matthiessen (2014) provide more specific descriptions of the transitivity system by adding subtypes to mental process, relational process and by providing more illustrations of options. Martin, Matthiessen, and Painter (2010) provide more comprehensive descriptions of participants by differentiating a causative and agentive role in a causative verbal group complex. Fawcett (Forthcoming) makes a further move in the delicacy of configurations in processes and also offers new explanations of material, relational, influential and environmental processes. In China, Cheng (1994) establishes the transitive and ergative systems for the material process and mental process. Hu et al. (2005) initiate refinements in the relational process by categorizing three subtypes and two modes. In addition to these two representative works, Xiao (1998), Huang (1998), Zhu and Yan (2001) and Cheng (2002) make new interpretations of the different parts of the transitivity system and help promote its application in various research fields. Later, topological studies of transitivity are developed to interpret other languages, including Long (1981), Li (2007), Long and Peng (2012) and He et al. (2017) on the Chinese transitivity system, Caffarel, Martin, and Matthiessen (2004) on French, Steiner and Teich (2004) on German, Teruya (2004) on Japanese, Moyano (2009) on Spanish, Martin (2004) on Tagalog, Rose (1996) on an Australian language Pitjantjatjara, and van Voorst (1996) on a comparison of Dutch, French and English transitivity system. Being the latest topological study, He et al. (2017) provide a comprehensive network of the Chinese transitivity system based on Halliday's prototype network and Fawcett's cognitive-oriented transitivity system, offering foundations for functional studies of Chinese discourses.

As Halliday approach of ecolinguistic studies takes on its momentum in recent decades, functional linguists are making efforts in exploring the appliability of systemic functional grammar and its interpretative power in discourse analysis, including 
Alexander and Stibbe (2014), Stibbe (2014, 2015), Huang (2017), He and Wei (2017), He and Zhang (2017), Zhang and He (2018), Zhang and Huang (2019). Some studies have explored the ecological potential of the metafunction networks, such as He and Zhang (2017) and Zhang (2018). Zhang and He (2018), Wei and He (2019) and He and Ma (2020) combine to establish a network of appraisal resources. Concerning the transitivity system, He and Wei (2017) propose a network for international ecological discourse analysis based on an ecosophy of harmony in diversity, reciprocity and mutual benefit. These system networks have enriched the theoretical reserve for the current ecolinguistic research and contributed to ecological discourse analysis. However, even with the strong momentum of ecolinguistic study, there is still a high demand for more systemic work to reveal the interpretative potential of lexicogrammatical resources with ecological criteria, rather than basing the discussion on existing discoursal frameworks such as critical discourse analysis or positive discourse analysis. ${ }^{2}$

Through the review as mentioned above, it can be concluded that the potential interpretative power of the transitivity system in construing and shaping ecological experiences has not been studied. Therefore this research intends to explore the appliability of the transitivity system under ecological criteria to contribute to the present landscape of ecolinguistic study with new system networks to draw on.

\section{Transitivity system within the lens of ecological sense of place}

By nature of an ecolinguistic study, the research follows a more or less standard theory of marking discourse ideologically to enhance or mitigate their beneficial or destructive influences. Therefore this section starts with a proposition of the ideologies behind this critical approach.

\subsection{Ecological sense of place}

For any ecolinguistic studies, the ecological criteria held by the researchers determine the way they see and evaluate the stories within texts. Coming from different backgrounds, researchers develop various understandings of ecology and therefore possess different ecological criteria, also known as ecosophy, a term introduced by Naess (1995). Once the researchers determine their ecosophies, they can use them as criteria to judge the ecological value of discourses. There are various philosophical frameworks for an ecosophy, including social ecology (e.g., Bookchin 2005), sustainable development (e.g., Baker 2006), deep green resistance (McBay, Keith, and Jensen 2011), ecofeminism (e.g., Adams and Gruen 2014), living (Stibbe 2015), harmony (Huang 2018), ecological sense of place (He and Zhang 2017; Zhang 2018; Zhang and He Forthcoming), diversity and harmony, interaction and co-existence (He and Wei 2018). This research believes that for any ecolinguistic studies, the end of the discussion falls on the topic of human-nature relationships. And as long as anyone lives, (s)he lives in a sustaining place. Based on this fundamental belief, we draw on an ecosophy named Ecological Sense of Place (hereafter ESOP), developed out of the framework of sense of place together with the traditional Chinese philosophies of Confucianism, Taoism and Buddhism (He and Zhang 2017; Zhang 2018; Zhang and He Forthcoming). The system network of ESOP is displayed in Figure 1. 


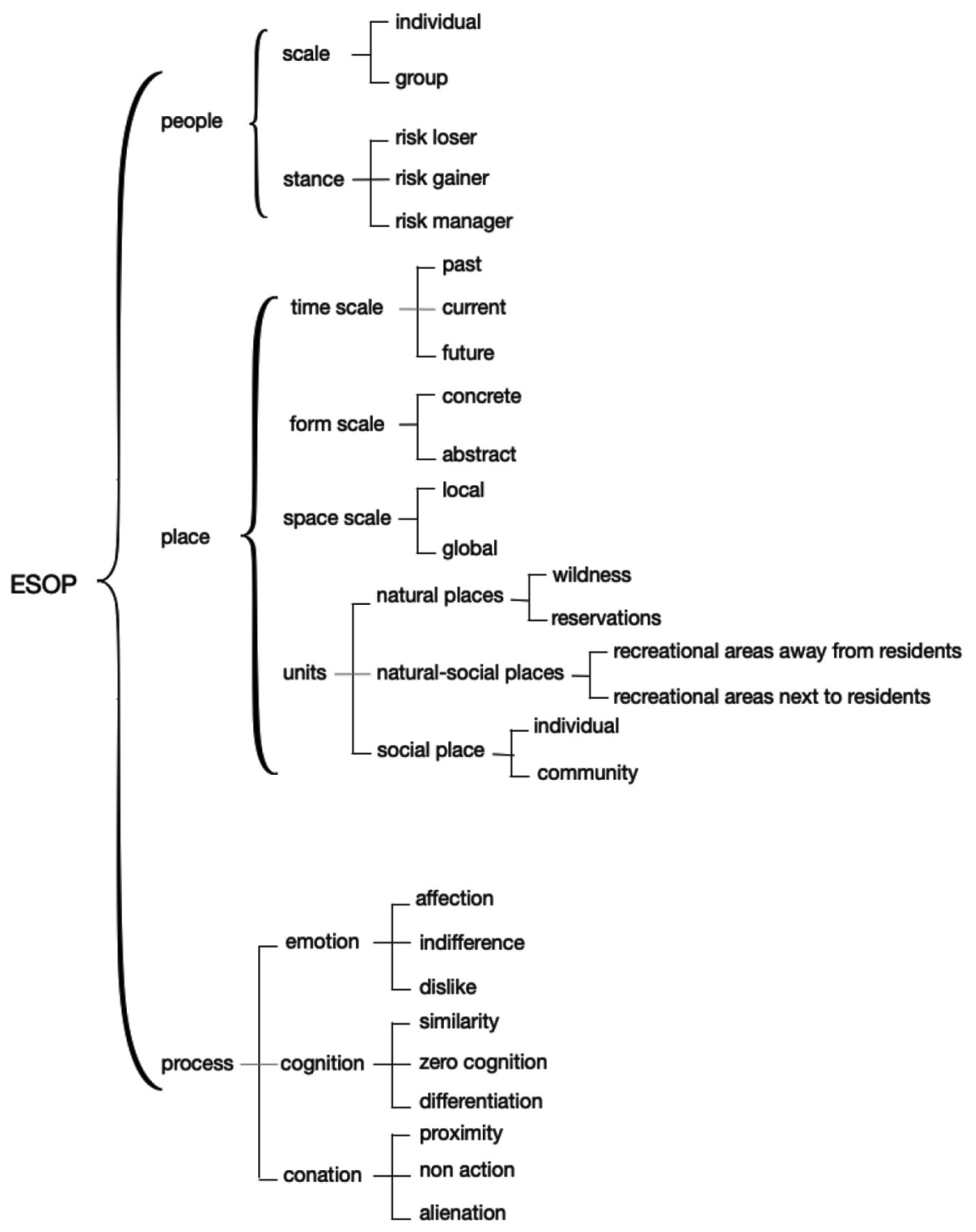

Figure 1. System network of Ecological Sense of Place (Zhang 2018; Zhang and He Forthcoming).

This network of ESOP works together with a syncretism of benevolence, frugality and intimacy with nature drawn from the traditional Chinese philosophies. The network serves as an analytical framework to sort out the involved parties in an ecological unit, or to be specific, a place that a living organism is posited. While describing the identities and the process types, we can evaluate the ecological impact following the syncretism. If the process meets these criteria, then this involved person holds a positive attitude toward the place and thus exerting a positive effect on the ecology. We explain this process through an example: 马克到附近公园走走散心 (make dao fujin gongyuan zouzou sanxin: Mark walked to the nearby park to release the stress). This particular situation can be analyzed with the following steps. There is an individual who expresses a sense of 
proximity to a concrete, local, natural place. This attachment to the place is also reflected by the belief that it can enact positive emotion within the protagonist. This phenomenon meets the criterion of having intimacy with nature. Therefore we could conclude that this particular situation in a way benefits the ecology as this affective emotion and intimacy toward nature will help promote more positive emotions and actions to the ecology in general. $^{3}$

This sense of place, whether being an introvert reflection or an overt display of actions, can be detected in the form of language. As the previous parts suggest, experiences, in the most direct form are construed in language as participants and processes in the transitivity system. In Halliday's system network of transitivity, the configuration of participants and processes are in line with different process types. The ecosophy connecting people, place and sense of place will serve as an ideological base to reveal which properties of the transitivity system can be consciously controlled to present ecologically friendly meaning. This research builds upon the transitivity system proposed by He et al. (2017), which is presented in Figure 2.

\subsection{Participants through the lens of ESOP}

A clause contains three types of components: a process, the participants and the circumstances. Participants are inherent in the process, and their nature varies according to the type of process set out in Figure 2. Looking through an ecological lens, participants, in their most original sense, are organic or inorganic compounds, constituting the life on earth and the inorganic world commonly understood as supporting systems. Within the organic world, human beings differentiate themselves from other organisms such as the animals, plants, fungi and microbes, contributing to the term of human and non-human organisms. In our language system, with differentiation of agentive role or affected role, participants can be divided into -er role or -ed role (Hasan 1985). In this section, we discuss the ecological power of participants as -er and -ed role in the transitivity system regarding their ecological niche.

\subsubsection{Scale of participants: individual vs. group}

Following the ESOP framework, it is observed that in terms of scale, people in living places can be divided into individual or group. For individuals, a place is significant with personal memories, contributing to a stable sense of self (Twigger-Ross and Uzzell 1996). Moreover, the individual exerts influence on a place in either delicate or drastic ways, creating experience-in-place meaning. For a group of people, attachment to a place is reflected in a collective process wherein they may practice. Taking these considerations into the transitivity system, we argue that for the participants of -er role or -ed role, the degree of influences construed through the process can be differentiated in terms of an individual or group scale. For 马克[Ag]到附近公园走走[Pro]散心 (make dao fujin gongyuan zouzou sanxin: Mark walked to the nearby park to release the stress) ${ }_{1}^{4}$ we believe that it is potentially beneficial to the ecology. If the Actor of 马克 (make: Mark) is changed into a collective participant, the family of Mark, we may argue that the potential of getting intimate to nature is enlarged to the degree of a group attachment. When an -ed role is involved, for example in 马克[Ag]到附近公园打[Pro]了一只鸟[Af] (make dao fujin gongyuan da le yi zhi niao: Mark went to the nearby park and shoot a bird), the affected 


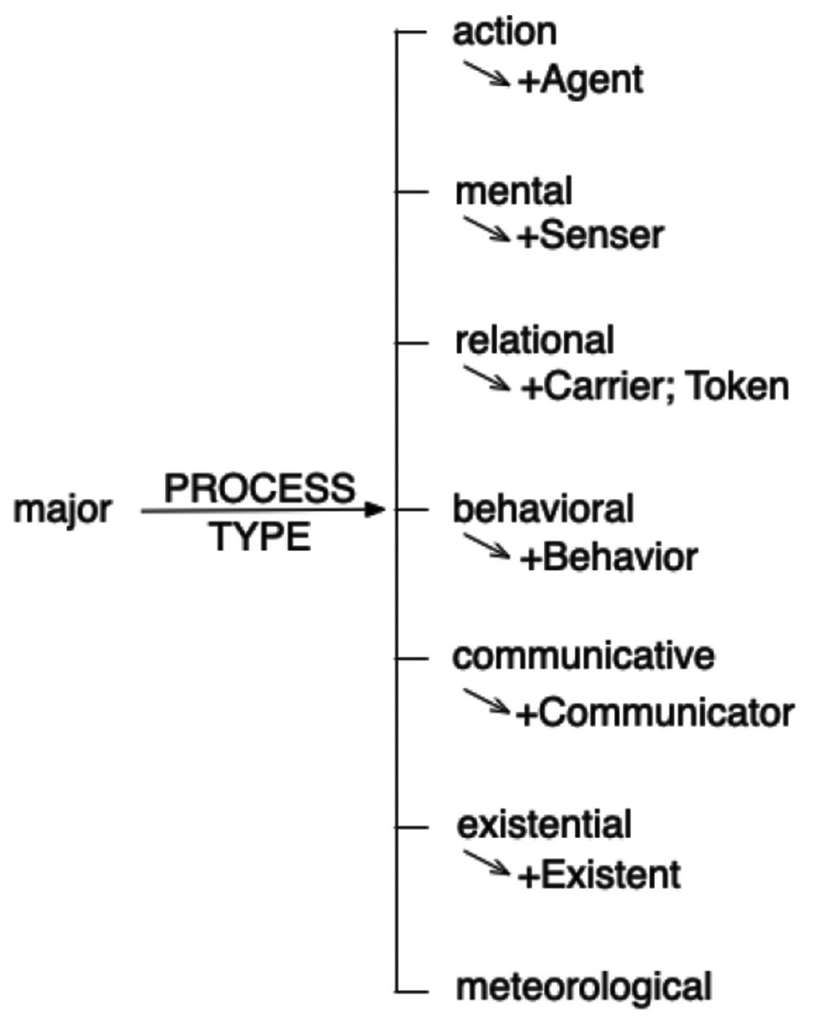

Figure 2. Transitivity system of Chinese.

participant also matters when it is an individual or group, i.e., a bird or lots of birds in this example. There are also cases when the -er or -ed role cannot be directly scaled as an individual or group. In 北京市[Ag]大力加强[Pro]水资源保护[Af] (beijingshi dali jiaqiang shuiziyuan baohu: Beijing has strengthened the protection of water resources), the -er role 北京市 (beijingshi: Beijing) can be regarded as a collective entity, but the -ed role 水资源 保护 (shuiziyuan baohu: the protection of water resources) cannot be assigned to either identity. In an example like this, we regard the -ed role as a collective participant as the protection of water resources matters collectively.

In facing global problems, individual actions have only a minuscule influence on collective outcomes (Olson 1965) and environmental problems can only be solved by the co-ordination of large numbers of people (Cranor 1985). Thus we propose to include the scale of individual or group to the participants involved in all types of processes to measure their degree of influences. ${ }^{5}$

\subsubsection{Stakeholders as participants}

An ecological discussion often involves striking a balance between the protection and use of natural resources, and this practice is typically complex, uncertain, multi-scale and affects multiple actors and agencies (Reed 2008). A diverse group of involved parties will 
bring together a variety of perspectives, motivations, past experiences and interests (Madden and McQuinn 2014). Therefore in complicated topics such as ecological protection, sustainability, energy conservation, a classification of the stakeholders in environmental issues is of great importance.

Stakeholders are broadly defined as the people and organizations who are involved in or affected by an action or policy and can be directly or indirectly included in the decisionmaking process (Freeman 1984; Annan 2007; Sterling et al. 2017). In the network of Figure 1 , the entry of people is divided into three types of stakeholders (stance), the risk loser, the risk gainer and the risk manager. The risk loser identifies those who may be adversely affected by an environmental risk action or decision regarding their health, economic, or social well-being and possibly their deeply held values (English 2000). Risk gainer refers to those who may be favorably affected, typically through economic gains and most possibly, those who create environmental risks. The risk manager is responsible for preventing or minimizing the risk. ${ }^{6}$ These three types of stakeholders bring about radically different perspectives to the environmental issues and therefore exerting different influences on the ecology. With this categorization, we can interpret the ecological effects of participants based on their representation of interests and concerns.

(1)

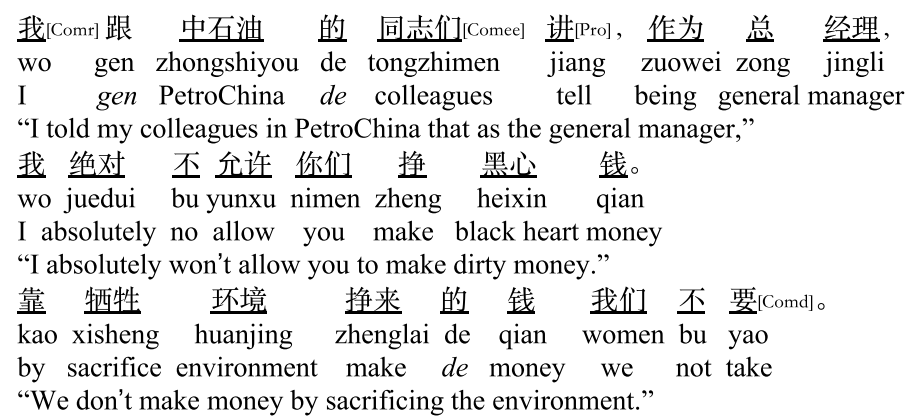

The extract is from an interview of a high official working for a mega oil company. The involved participants include the -er role of 总经理 (zongjingli: the general manager) and the -ed role of 中石油的同志们 (zhongshiyou de tongzhimen: my colleagues in PetroChina). Both the -er role and -ed role can be regarded as risk gainers with their potential to gain economically if they decide to ignore the balance of protecting the environment and using natural resources. However, in this communicative process, the manager describes how he forbids all his colleagues from taking illegal methods to earn money and not making a profit by scarifying the environment. Therefore he takes on the role of risk manager by making decisions to curb environmental risks. This change of stance is backed up by a belief that natural resources should not be depleted for commercial purpose, therefore taking a middle ground in-between being benevolent to the environment and not being greedy of opulence. Based on these analyses, we can conclude that in this text, a risk gainer switches his stance to risk manager with ecological awareness beneficial to the ecology, making this text an ecologically beneficial one. 


\subsubsection{Circumstantial role of place}

The previous two sections discuss the potential of ecological implications from the participants, mainly through the interpretation of the role of human beings. This section turns to the critical component of the people-place relationship, the function of place in the transitivity system. A place appears in various process types. In the system network of He et al. (2017), there is a participant of Direction: destination, such as in 猎队[Ag]将[PrEx] 羚羊[Af-Ca]赶[Pro]到[PrEx]了悬崖边[Dir: Des] (liedui jiang lingyang gan dao le xuanya bian: A hunting team forces a group of gazelle to the edge of a cliff). 悬崖边 (xuanya bian: the edge of a cliff) is understood as an indispensable participant of the action process of 赶到 (gan dao: force ... to ...). A place can appear as the Phenomenon of a mental process, such as 他[Em]从小就热爱[Pro]家乡的山山水水[Ph] (ta congxiao jiu reai jiaxiang de shanshanshuishui: He developed a love for the mountains and waters in his hometown at a young age). A place can also be frequently found in the relational process as Carrier, Attribute, Token, Value, Location (also in the existential process), Source, Destination, Possessor, Possessed and Correlator. An example of this would be 熊猫和 和[Ca]居住[Pro]在美丽的竹子林里[Loc] (xiongmao hehe juzhu zai meili de zhuzi lin li: The giant panda Hehe lives in a beautiful bamboo forest). As for the communicative and behavioral process, a place can appear as participants, but in the form of personification.

Beyond these cases as participants, a place is generally regarded as a supportive role, nestled in the label of circumstance in the transitivity system. Circumstantial roles, as Halliday and Matthiessen $(2014,221)$ remarks, "are more peripheral and unlike participants, they are not directly involved in the process." In the example 马克到附近公园走走 散心 (make dao fujin gongyuan zouzou sanxin: Mark walked to the nearby park to release the stress), 附近公园 (fujin gongyuan, the nearby park), which is the destination of the -er role Mark, works as a circumstance to the action process. However, if we follow the analytical network of transitivity system and leave out the circumstantial role in this process, its ecological value is severely downplayed. In example 马克[Ag]到附近公园打 [Pro]了一只鸟[Af] (make dao fujin gongyuan da le yi zhi niao: Mark went to the nearby park and shoot a bird), we cannot decide if the bird means a real one were it not for the place of 附近公园 (fujin gongyuan: the nearby park) since it can be a virtual image in a video game. Again the ecological implication of this clause would be misguided without the circumstantial role of place.

As this research places much emphasis on the people-place relationship and also believes that a place matters more than just a supportive role, it is suggested that the circumstantial role of place should be highlighted as a crucial contributor to the construing of ecological meaning in a clause. This particular action serves two purposes: firstly, it brings to the front stage the living places that sustain and constitute human existence; secondly, it embodies the position of the human being as a component rather than a ruler of the living environment.

\subsection{Processes within the lens of ESOP}

Clauses containing different process types make distinctive contributions to the construal of experience (Halliday and Matthiessen 2014). For an experience, we have different ways to semanticize it. For example, the meaning of 马克到附近公园 走走散心 (make dao fujin gongyuan zouzou sanxin: Mark walked to the nearby park 
to release the stress) can be expressed as 到附近公园走走能让马克散散心 (dao fujin gongyuan zouzou neng rang make sansan xin: A walk in the nearby park can release Mark's stress) or 到附近公园走走是一件能让马克散心的事 (dao fujin gongyuan zou zou shi yi jian neng rang make sanxin de shi: A walk in the nearby park is a stress-releaser for Mark). ${ }^{7}$ These three clauses, representing two action processes with different actors and a relational process, basically construe the same experience involving the elements of 马克 (Mark)，走走 (zouzou: a walk)，附近公园 (fujin gongyuan: the nearby park), 散心 (sanxin: release the stress). It is all about a person finding release in a place by taking specific actions and following certain beliefs that he can achieve a stable mind with this action. Therefore disregarding the subtle differences with a different representation of processes, the ecological implication of the three examples is not so different from each other. It can be explained by the fact that within any type of process, the attitude of the involved person toward a place is no other than three types, an emotive one, a cognitive one and a conative one. In this particular example, Mark holds an affectionate attitude toward the nearby park and believes that intimacy with nature would help relieve his stress. The interpretation is based on the comprehensive understanding of the participants, the process and the circumstance, rather than merely on the predicate that differentiates process types. Therefore we propose that it is necessary to decide the process meaning through a lens of the three process types of ESOP to reveal the people-place relationship thoroughly. The working scheme is that after recognizing the processes, participants and circumstances that constitute a particular semantic configuration, a second-layer discussion of whether this configuration embodies positive or negative emotional, cognitive or conative attitudes from the speaker/writer should be initiated.

\subsubsection{Action process}

An action process construes the flow of events through some input of energy, involving participants such as Actor, Affected, Created, and sometimes Affected-Carrier, Manner and Direction. Based on the transitivity system of Chinese, the semantic structure of the following two examples are presented.

(2)

$$
\begin{aligned}
& \text { 第一届虫国 国际 写戏 节[Cre] 在 珠海 横琴[Cir] 隆重 兴行[Pro]。 } \\
& \text { diyi jie zhongguo guoji maxi jie zai zhuhai hengqin longzhong juxing } \\
& \text { first time China international circus festival at Zhuhai Hengqin grandly launch } \\
& \text { "The 1st China International Circus Festival was launched grandly in Heng Qin, Zhu Hai." }
\end{aligned}
$$

\footnotetext{
经过 十多年努力, 我国西北防护㷊带[Cre] 已初步建成[Pro]。 Jingguo shi duo nian nuli wo guo xibei fanghu lin dai yi chubu jiancheng through ten over year effort me country southwest shelter forest belt already preliminary create "Through over ten years of effort, our country's southwest shelter forest belt is created."
} 
To interprete their ecological value, we need to decide the attitude of the speaker/writer through several indicators. To begin with, both of the clauses include a Created participant without any Actor, therefore there will be no further discussion of the scale and stance of the agentive role. Besides, both of these clauses contain a place, in example (2) 珠海横琴 (Hengqin, Zhuhai) and in example (3) 我国西北 (woguo xibei: southwest of China). The first place is a specific, local community, while the latter one represents grand wildness.

For example (2), the speaker/writer uses positive appraisal resources of 隆重 (longzhong: grandly) to indicate his/her affective attitude toward the launching of the circus festival. Human beings taking pleasure in the suffering of non-human animals causes more than moral problems, but also rarity and vulnerability of the species of the animal concerned. Activists for animal rights as well as environmentalists have gradually recognized the human/animal continuation rather than the human/animal opposition. Thus promotion of such an event in this particular place cannot be regarded as beneficial to the ecology. For example (3), the Created element is the "Chinese southwest shelter forest belt", which is made to slow wind erosion, and also to protect the land and underground water. This clause is likely to be found in govern reports or news page, to publicize the Chinese government's effort in protecting the ecology. Clauses like this constitute the typical beneficial discourses and should be promoted to raise group awareness.

\subsubsection{Mental process}

A mental process is concerned with the experience of the world of consciousness, containing participants such as Emoter, Perceiver, Cognizant and Phenomenon. Example (4) and (5) provide two mental processes with semantic structures outlined.

(4)

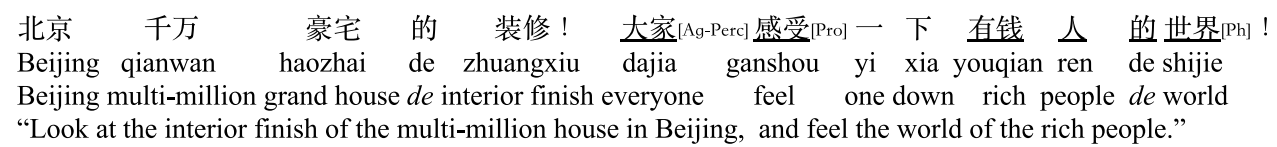

(5)

看见大量的被屠杀的鲸鱼 散布 在 地, 在 场 的 [ $\mathrm{Em}]$ 心里 难过 $[\mathrm{pro}]$ 极了。 kanjian da liang de bei tusha de jingyu sanbu zai di zai chang de ren xinli nanguo ji le see large amount de bei slaughter $d e$ whales spread at ground at place de people heart sad extreme le "Seeing the large amount of slaughtered whales spreading around, people there felt extremely sad."

Example (4) includes a place as personal property and its visitors with a promotive sense. It serves to develop a sense of desire among the Agent-Perceivers for places like 千万豪宅 (qianwan haozhai: multi-million house). The participants involved have the potential of becoming risk gainers if they follow such extravagant living style, inflicting more pressure on the environment with industrial products and potential wastes. Affective attitude toward places like this does not meet the ecosophy of frugality. Therefore what is 
constructed in this clause is eco-destructive and should not be promoted. Example (5) includes a scene or a place where a group of people is looking at slaughtered whales. Based on the contexts, the participants are not risking gainers and are likely to be risk losers or risk managers, and their negative emotion toward the scene will probably lead to resistance to such behaviors. Besides, the negative emotions from the participants toward such a scene reflect a sense of benevolence, therefore making this clause a beneficial one to the ecology.

\subsubsection{Relational process}

The relational process serves to characterize and to identify, involving participants of Carrier, Attribute, Token, Value, Location, Source, Path, Destination, Possessor, Possessed, and Correlator. The following two examples represent the possessive process and directional process. ${ }^{8}$

(6)

一般 来 说 竹节 纹 表 带[Ca]聚 $\frac{\text { 自 }[\text { Pro] 鳄鱼 的腹部 虫间 位置[So]。 }}{\text { yiban lai shuo zhujie wen biao dai qu zi eyu de fubu zhongjian weizhi }}$
common come say slubbed line watch band get from crocodile de belly middle place
"Commonly speaking, the watch band with slub pattern is made of crocodile belly skin."

(7)

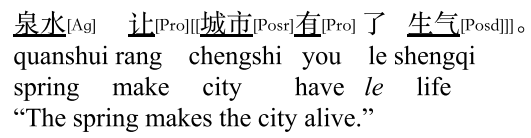

Both of these two examples include a place that works as a participant, in example (6) 鳄鱼的腹部中间位置 (eyu de fubu zhongjian weizh: the central part of crocodile belly) and in example (7) 城市 (chengshi: the city). For example (6), the place is exceptional, as itself is part of the living organism. Ironically, the connection between the Carrier and the location is one between something belonging to the human world and somewhere from the non-human organism. Unlike ordinary occupation and utilization of a place, this particular interaction between people and the place is fatal, bearing no benevolent attitude to the living creatures. Therefore the experience represented in this clause is by no means beneficial to the ecology. For example (7), a causative process happens when 泉水 (quanshui: spring) is regarded as an agentive role in making the city (where human presence is embedded as passive role) alive. It is evident that the speaker/writer has affectionate feelings toward this place and also believes that being intimate with nature makes a city better. Following our ecosophy, this clause exerts beneficial effects on the ecology.

\subsubsection{Behavioral process}

The behavioral process sits in-between the material and mental process to construe physiological and psychological behavior. The participant is typically a conscious being 
labeled Behaver. In processes like this, a place appears normally as the circumstantial role.

我们站 在 船 头, 拿着 丈八 长 的 镖杆, 眼睛[Behr] 紧紧 䢸[Pro] 着 海 面[Ra] 搜寻 尾鳍。 women zhan zai chuan tou na zhe zhangba chang de biaogan yanjing jinjin ding zhe hai mian souxun weiqi we stand at boat head, hold zhe ten-feet long de shaft eye firmly stare zhe sea surface search tail fin "We stood at the fore, holding ten-feet long shafts and stared firmly at the sea surface to look for the tail fin."

(9)

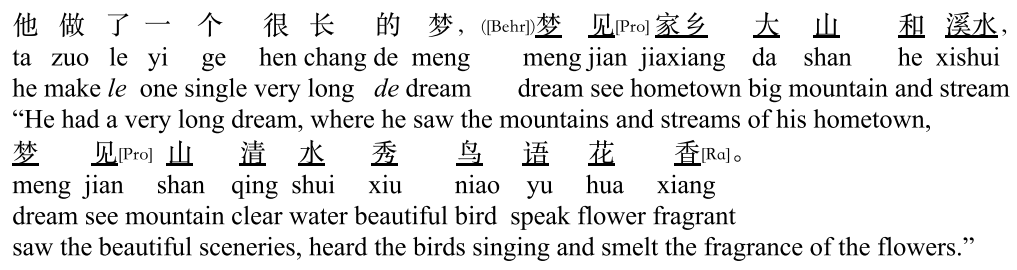

In the above two examples, people-place interacts can be overtly identified. For example (8), the place is the Range of a behavioral process of watching. Together with the preceding information of standing at the deck of a boat and holding 18 feet shafts in hand, the behavioral process describes an experience of hunting for shark at sea, which is not consistent with the ecosophy of having benevolence to the non-human creatures. For example (9), the participant develops a sense of proximity to his hometown and the scenery in a behavioral process of dreaming. The speaker/writer describes the attractiveness of a place in nature and also an intimacy to this place, which according to the ecosophy proposed before, brings beneficial effects to the ecology. Therefore based on the analysis, we can conclude that these two have opposite ecological orientations.

\subsubsection{Communicative process}

This process contributes to the accounts of dialogue, with the process of saying interpreted in a broad sense, including any kind of symbolic exchange of meaning. The configurations of this process type contain participants of Communicator, Communicatee and Communicated. ${ }^{9}$

\footnotetext{
马戏团 海报 上[Comr] 写[Pro] 着“免费 和 老虎 合 影”[Comd]。 maxituan haibao shang xie zhe mianfei he laohu he ying circus poster up write zhe free and tiger join photo "On the poster of the circus there wrote, take a picture with the tiger for free."
}

$$
\begin{aligned}
& \text { 美 研究[Comr] 表明[Pro] 地球 } \\
& \text { mei y气 } \\
& \text { America research demonstrate earth atmosphere self clean ability decrease }
\end{aligned}
$$$$
\text { "American research demonstrates that the self-cleaning ability of the earth's atmosphere has decreased." }
$$ 
For example (10), the event happens most possibly in a circus where people go to see the show of imprisoned animals. The presence of the place, a circus operated within the social community, is embedded in the clause as part of the risk gainer participant. The peopleplace interaction is the potential of people going to such a place incited by the promotion of 免费和老虎合影 (mianfei he laohu heying: taking a picture with the tiger for free). By the standard of being benevolent to all living creatures with respect, the construed meaning of caging wild animals for commercial purposes is not beneficial to the ecology. For example (11), the people-place interaction is human beings studying the earth's atmosphere, which is the living environment for themselves. The clause presents the fact that the natural environment is having a problem, therefore raising people's awareness toward the shared living place. Thus this communicative process construes beneficial meaning to the ecology.

\subsubsection{Existential process}

In construing the existence of an entity in a particular place, the existential process in nature includes a place as a participant. While some of the processes construe peopleplace relationships directly, some construe indirectly.

$$
\begin{aligned}
& \text { 屋肉墙 上[Loc] 挂[Pro]着硕大 的鹿角[Ext], 是他花 高价买来 的。 } \\
& \text { wu nei qiang shang gua zhe shuoda de lujiao shi ta hua gao jia mai lai de } \\
& \text { room inside wall up hang zhe huge de antler is he spend high price buy come de } \\
& \text { "On the wall inside the room, there hangs a huge antler, bought by him with a high price" }
\end{aligned}
$$

$$
\begin{aligned}
& \text { 水面上[Loc] 流动[Pro] 着 臀蓝 色的玉 光一白 絮 般的云朵[Ext]。 } \\
& \text { shui mian shang liudong zhe weilan se de tian guang bai } \mathrm{xu} \text { ban de yunduo } \\
& \text { water surface up flow zhe cerulean color de sky light white catkin like de cloud } \\
& \text { "On the surface of the water, there floats cerulean light and cotton-like clouds." }
\end{aligned}
$$

These two examples depict two different types of place, one with human beings and another without human presence. In example (12), the place is 屋内墙上 (wunei qiangshang: on the wall inside the room), which is a human-related place while the Existent is 硕大的鹿角 (shuoda de lujiao: a huge antler), which represents an animal. The existential process implies preceding experiences of killing, selling and purchasing of the deer for commercial purposes and also indicates people's appreciation of antler as decorations. Neither of these two facts respects the ecosophy of showing benevolence to other creatures, therefore delivering a negative message to the readers. Example (13) construes a scene of nature with water, sky and clouds interacting with each other, without any human presence. This description is made out of the speaker/writer's intimate observation of nature with keen and affective senses. Therefore the clause is delivering information beneficial to the construction of human knowledge of nature. 


\subsubsection{Meteorological process}

The meteorological process resides between the existential and action process. The basic configuration of the meteorological process consists only of a Process element and a ProcessExtension element. The Process is typically realized by verbs such as 下 (xia: drop down) and 刮 (gua: blow). The ProcessExtension is commonly realized by words such as 雨 (yu: rain), 雪 (xue: snow) and 风 (feng: wind). Some of the typical processes are 下雪了 (xia xue le: it is snowing/snowed) and 打雷了 (da lei le: it is thundering). Though this type of process directly reflects the phenomenon of nature, it does not reflect much ecological implication with its lack of human attitude.

However, there are many other metaphorical ways of construing climates or weather conditions. For example, in 强冷空气将袭击我国大部分地区 (qiang leng kongqi jiang xiji woguo da bufen diqu: A strong cold air will hit most parts of our country), there is a placebased experience in which 强冷空气 (qiang leng kongqi: a strong cold air) is regarded as an attacker. The use of 袭击 (xiji: hit) represents the speaker/writer's negative emotion toward the meteorological phenomenon, therefore consolidating people's oppositional attitude toward nature. Examples like this are abundant, especially in weather forecasts. Therefore it is suggested that for the benefits of a harmonious attitude toward nature, clauses about meteorological information should avoid depicting the natural phenomenon as enemies to human beings, but instead as warnings of deteriorating human-nature relationships.

\section{Summary}

Overall, the premise of this research is that ecolinguistic studies can interpret experiences between people and place construed through the transitivity system and by questioning and challenging these experiences from an ecological perspective, it is possible to build up new stories that are beneficial to a harmonious relationship between human and nature in general.

The research develops this interpretative approach by firstly proposing a set of ecological criteria termed as Ecological Sense of Place, which is based on theories from the field of human geography and traditional Chinese philosophies. With this ecosophy in mind, we set out to discuss how the transitivity system of Chinese and lexicogrammatical resources for construing experiences work to reflect and shape people-place interactions. The discussion focuses both on the participants and the processes. For participants, the research proposes to examine the role of participants in making stories of human-nature relationships concerning the scale and stance of people involved in an experience. Intricate degrees of effect can be sorted according to the presence of the participant in the unit of people-place interaction. Besides, the circumstantial role of place is emphasized as an indicator in analyzing the ecological values of a clause. For the processes initially classified in the transitivity system, the research suggests a further interpretation of the emotive, cognitive and conative attitude reflected by them. This suggestion is supported by example analysis of the seven process types in the Chinese transitivity system.

The research serves several purposes: 1) it explores an approach of ecolinguistic study through the lens of people-place interaction, which constitutes a significant part of the human-nature relationship; 2 ) it extends the interpretative potential of Chinese transitivity system with a valid ecosophy; 3 ) it embodies the possibility of revealing embedded ecological stories through the grammar of the language itself as well as through how language is used in construing experiences. 


\section{Notes}

1. Alwin Fill (1998) identified two approaches to the study of ecolinguistics, the Haugen approach and the Halliday approach. For the Haugen approach, "ecology" is understood metaphorically and concerns language(s) in an environment. For the Halliday approach, "ecology" is understood in its biological sense. This research follows the insight of the Halliday approach, and for further discussion of the Haugen approach, please refer to Haugen (1972).

2. Discussions about whether an ecolinguistic study should be based on its principles, methodologies and analyzing frameworks could be found in Huang (2018), He and Wei (2018), He and Gao (2019).

3. This is not an absolute judgment as in an extreme case, and this particular person may also decide to take his garbage out and throw it in the forest while walking. The example is provided as an explanation for the working scheme of the ecosophy. Reliable decisions can only be made based on specific contexts.

4. Examples in this research are from online resources, with minor modifications. The semantic configuration is displayed following the pattern of He et al. (2017). Key for the abbreviations in this research: Pro $=$ Process, $\mathrm{PrEx}=$ ProcessExtension, $\mathrm{Cir}=$ Circumstance $\mathrm{Ag}=\mathrm{Agent}, \mathrm{Af}=$ Affected, $\mathrm{Em}=$ Emoter, $\mathrm{Ph}=$ Phenomenon, $\mathrm{Comr}=$ Communicator, Comee $=$ Communicatee, Comd $=$ Communicated, Ag-Perc $=$ Agent-Perceiver, Af-Ca $=$ Affected-Carrier, Dir: Des $=$ Direction: Destination, $\mathrm{Cre}=$ Created, Ext $=$ Existent, $\mathrm{Loc}=$ Location, $\mathrm{Ra}=$ Range, So $=$ Source .

5. Existential processes and meteorological processes are excluded since their participants typically have different references.

6. These categories are not mutually exclusive. A risk loser also might be a gainer in some respects, for example, through new employment opportunities.

7. The two variant examples of "Mark walking in the park to release the stress" are by no means typical expressions. The research uses them to indicate the same ecological potential of different process types.

8. The possessive process and the directional process both belong to the relational process following the framework of $\mathrm{He}$ et al. (2017). The possessive process construes the ownership between the Possessor and the Possessed entities, expressed either as "somebody owns something" (Posr + Pro + Posd) or "something belongs to somebody" (Posd + Pro + Posr). The directional process realizes the relationship between entities and their origins, paths and destinations, containing Participants of the Carrier, the Source, the Path, or the Destination.

9. According to He et al. (2017), the communicative process represents more than the verbal process defined by Halliday but includes a sense of "intentionality" in such processes and rules out specific events that can be regarded as behavioral processes.

\section{Acknowledgments}

This study was supported by Major Program of National Social Science Fund of China: Database Construction of Language Resources of Those Countries along the Belt and Road and Contrastive Studies between Chinese and Foreign Languages (19ZDA319) and Fundamental Research Funds for the Central Universities, P. R. China: Construction of Ecological Discourse Analysis (FRF-TP-18-085A1).

\section{Disclosure statement}

No potential conflict of interest was reported by the author(s).

\section{Funding}

This work is supported by National Social Science Fund of China [19ZDA319] and Fundamental Research Funds for the Central Universities [FRF-TP-18-085A1]. 


\section{Notes on contributors}

Ruijie Zhang, PhD of literature, is a lecturer of linguistics with School of Foreign Studies (SFS) in University of Science and Technology Beijing (USTB). She is also a member of the Association Committee of China Association of Ecolinguistics. Email: zhangruijie@ustb.edu.cn.

Wei $\mathrm{He}, \mathrm{PhD}$ of literature, is Professor of Linguistics and PhD supervisor with National Research Centre for Foreign Language Education, Beijing Foreign Studies University (BFSU). She is at the same time the Chair of China Association of Ecolinguistics. Email: francesweihe@aliyun.com.

\section{ORCID}

Ruijie Zhang (D) http://orcid.org/0000-0001-6861-5640

\section{References}

Adams, C., and L. Gruen. 2014. Ecofeminism: Feminist Intersections with Other Animals and the Earth. London: Bloomsbury.

Alexander, R., and A. Stibbe. 2014. "From the Analysis of Ecological Discourse to the Ecological Analysis of Discourse." Language Sciences 41 (Part A): 104-110. doi:10.1016/j. langsci.2013.08.011.

Annan, K. 2007. "How to Engage Stakeholders and Mainstream Biodiversity." In Communication, Education and Public Awareness (CEPA): A Toolkit for National Focal Points and NBSAP Coordinators, edited by F. Hesselink, W. Goldstein, P. P. van Kempen, T. Garnett, and J. Dela, 155-225. Montreal: Secretariat of the Convention on Biological Diversity and IUCN.

Baker, S. 2006. Sustainable Development. London: Routledge.

Bookchin, M. 2005. The Ecology of Freedom: The Emergence and Dissolution of Hierarchy. Oakland, CA: AK Press.

Caffarel, A., J. R. Martin, and C. M. I. M. Matthiessen. 2004. Language Typology: A Functional Perspective. Amsterdam: John Benjamins Publishing.

Cheng, Q. L. 1994. Xitong Gongneng Yufa Daolun [An Introduction to Systemic Functional Grammar]. Shantou: Shantou University Press.

Cheng, X. T. 2002. "Guanyu Jiwuxing Xitong Zhong Guanxi Guocheng De Liangdian Cunyi [Two Problems about the Relational Process in Transitivity]." Modern Foreign Languages 3: 311-317.

Cranor, C. F. 1985. "Collective and Individual Duties to Protect the Environment." Journal of Applied Philosophy 2 (2): 243-259. doi:10.1111/j.1468-5930.1985.tb00037.x.

English, M. R. 2000. "Who are the Stakeholders in Environmental Risk Decisions - How Should They Be Involved." RISK: Health, Safety \& Environment 11: 243-254.

Evernden, N. 1978. "Beyond Ecology: Self, Place, \& the Pathetic Fallacy." The North American Review 263 (4): 16-20.

Fawcett, R. P. Forthcoming. The Functional Semantics Handbook: Analyzing English at the Level of Meaning. London: Equinox.

Fill, A. 1998. "Ecolinguistics - State of the Art 1998." AAA - Arbeiten aus Anglistik und Amerikanistik 23 (1): 3-16.

Freeman, R. E. 1984. Strategic Management: A Stakeholder Approach. Cambridge: Cambridge University Press.

Halliday, M. A. K. 1990. "New Ways of Meaning: A Challenge to Applied Linguistics." Journal of Applied Linguistics (Ninth World Congress of Applied Linguistics Special Issue) 6: 7-36.

Halliday, M. A. K. 1994. An Introduction to Functional Grammar. 2nd ed. London: Arnold.

Halliday, M. A. K., and C. M. I. M. Matthiessen. 1999. Construing Experience through Meaning: A Language-based Approach to Cognition. London/New York: Cassell.

Halliday, M. A. K., and C. M. I. M. Matthiessen. 2014. An Introduction to Functional Grammar. 4th ed. London: Routledge. 
Harvey, P. M. 2001. "Landscape and Commerce: Creating Contexts for the Exercise of Power." In Contested Landscapes: Movement, Exile and Place, edited by B. Bender and M. Winer, 197-210. Oxford: Berg.

Hasan, R. 1985. Linguistics, Language and Verbal Art. Victoria: Deakin University.

Haugen, E. 1972. "The Ecology of Language." In The Ecology of Language: Essays by Einar Haugen, edited by A. S. Dil, 344-366. Stanford: Stanford University Press.

Hausmann, A., R. Slotow, J. K. Burns, and E. D. Minin. 2016. “The Ecosystem Service of Sense of Place: Benefits for Human Well-being and Biodiversity Conservation." Environmental Conservation 43 (2): 117-127.

He, W., and R. Gao. 2019. "Shengtai Yuyanxue Yanjiu Zongguan [Review of Ecolinguistics]." Journal of Zhejiang International Studies University 1: 1-12.

He, W., and Z. J. Ma. 2020. "Shengtai Yuyanxue Shijiao Xia De Pingjia Xitong [Appraisal System from an Ecolinguistic Perspective]." Journal of Foreign Languages 1: 48-58.

He, W., and R. Wei. 2017. "Guoji Shengtai Huayu De Neihan Ji Yanjiu Luxiang [Definition and Research Method of International Ecological Discourse]." Foreign Languages Research 5: 18-24.

He, W., and R. Wei. 2018. "Huayu Fenxi Fanshi Yu Shengtai Huayu Fenxi De Lilun Jichu [The Paradigm of Discourse Analyses and the Theoretical Foundation of Ecological Discourse]." Contemporary Rhetoric 5: 63-73.

He, W., and R. J. Zhang. 2017. "Shengtai Huayu Fenxi Moshi Goujian [An Ecological Analysis Framework for Discourse]." Foreign Languages in China 5: 56-64.

He, W., R. J. Zhang, F. Zhang, X. H. Dan, and R. Wei. 2017. Hanyu Gongneng Yuyi Fenxi [Functional Semantic Analysis of Chinese]. Beijing: Foreign Language Teaching and Research Press.

Heise, U. K. 2008. Sense of Place and Sense of Planet: The Environmental Imagination of the Global. Oxford: Oxford University Press.

Hu, Z. L., Y. S. Zhu, D. L. Zhang, and Z. Z. Li. 2005. Xitong Gongneng Yuyanxue Daolun [An Introduction to Systemic Functional Linguistics]. Beijing: Peking University Press.

Huang, G. W. 1998. "Yingyu Shiyi Jiegou De Gongneng Fenxi [Functional Analysis of English Causative Structure]." Journal of Foreign Languages 1: 12-16.

Huang, G. W. 2017. "Cong Xitong Gongneng Yuyanxue Dao Shengtai Yuyanxue [From Systemic Functional Linguistics to Ecolinguistics.]." Foreign Language Education 5: 1-7.

Huang, G. W. 2018. "Cong Shengtai Piping Huayu Fenxi Dao Hexie Huayu Fenxi [From Eco-critical Discourse Analysis to Harmonious Discourse Analysis]." Foreign Languages in China 4: 39-46.

Jorgensen, B., and R. Stedman. 2001. "Sense of Place as an Attitude: Lakeshore Owners' Attitudes toward Their Properties." Journal of Environmental Psychology 21: 233-248.

Li, E. S. H. 2007. A Systemic Functional Grammar of Chinese. London: Continuum.

Long, R. J. 1981. "Transitivity in Chinese." MA Thesis, Sydney: University of Sydney.

Long, R. J., and X. W. Peng. 2012. Xiandai Hanyu Jiwuxing Yanjiu [On Transitivity of Modern Chinese]. Beijing: Peking University Press.

Madden, F., and B. McQuinn. 2014. “Conservation's Blind Spot: The Case for Conflict Transformation in Wildlife Conservation." Biological Conservation 178: 97-106.

Martin, J. R. 2004. "Metafunctional Profile: Tagalog." In Language Typology: A Functional Perspective, edited by A. Caffarel, C. M. I. M. Matthiessen, and J. R. Martin, 255-304. Amsterdam: John Benjamins.

Martin, J. R., C. M. I. M. Matthiessen, and C. Painter. 2010. Deploying Functional Grammar. Shanghai: Commercial Press.

Matthiessen, C. M. I. M. 1995. Lexicogrammatical Cartography: English Systems. Tokyo: International Language Science Publishers.

McBay, A., L. Keith, and D. Jensen. 2011. Deep Green Resistance: Strategy to Save the Planet. New York: Seven Stories Press.

Moyano, E. I. 2009. "Exploring Verbal Processes in Discussion of Academic Articles in Spanish." The 36th International systemic Functional Congress, Beijing.

Mühlhäusler, P., and P. Mühlhäusler. 2003. Language of Environment: Environment of Language: A Course in Ecolinguistics. London: Battlebridge Publications. 
Naess, A. 1995. "The Shallow and the Long Range, Deep Ecology Movement." In The Deep Ecology Movement: An Introductory Anthology, edited by A. Drengson and Y. Inoue, 3-10. Berkeley, CA: North Atlantic Books.

Olson, M. 1965. The Logic of Collective Action: Public Goods and the Theory of Groups. Cambridge and London: Harvard University Press.

Reed, M. S. 2008. "Stakeholder Participation for Environmental Management: A Literature Review." Biological Conservation 141 (10): 2417-2431.

Rose, D. 1996. "Pitjantjatjara Processes: An Australian Experiential Grammar." In Functional Descriptions: Language Form \& Linguistic Theory, edited by R. Hasan, D. Butt, and C. Cloran, 287-322. Amsterdam: Benjamins.

Sapir, E. 1912. "Language and Environment." American Anthropologist 14 (2): 226-242.

Steiner, E., and E. Teich. 2004. "German: A Metafunctional Profile." In Language Typology: A Functional Perspective, edited by A. Caffarel, C. M. I. M. Matthiessen, and J. R. Martin, 139-184. Amsterdam: John Benjamins.

Sterling, E. J., E. Betley, A. Sigouin, A. Gomez, A. Toomey, G. Cullman, C. Malone, et al. 2017. "Assessing the Evidence for Stakeholder Engagement in Biodiversity Conservation." Biological Conservation 209: 159-171.

Stibbe, A. 2014. "An Ecolinguistic Approach to Critical Discourse Studies." Critical Discourse Studies 11 (1): 117-128.

Stibbe, A. 2015. Ecolinguistics: Language, Ecology and the Stories We Live By. New York: Routledge.

Teruya, K. 2004. "Metafunctional Profile of the Grammar of Japanese." In Language Typology: A Functional Perspective, edited by A. Caffarel, C. M. I. M. Matthiessen, and J. R. Martin, 185-254. Amsterdam: John Benjamins.

Tuan, Y. F. 1977. Space and Place: The Perspective of Experience. Minneapolis: University of Minnesota Press.

Twigger-Ross, D., and D. L. Uzzell. 1996. "Place and Identity Processes." Journal of Environmental Psychology 16: 205-220.

van Voorst, J. 1996. "Some Systematic Differences between the Dutch, French and English Transitive Construction." Language Sciences 18 (1): 227-245.

Wei, R., and W. He. 2019. “Guoji Shengtai Huayu Zhi Jieru Xitong Fenxi Moshi Jiangou [An Analytical Framework of Engagement for International Ecological Discourse]." Journal of PLA University of Foreign Languages 6: 91-99.

Xiao, J. H. 1998. "Danyi Canyuzhe Juese Guocheng De Gongneng Fenxi [A Functional Analysis of One-participant-role Process.]." In Yuyan De Gongneng-Xitong, Yuyong He Renzhi [Language FunctionsSystem, Cognition and Pragmatic Principles], edited by K. S. Yu, H. L, and X. W. Peng, 139-145. Chongqing: Chongqing University Press.

Zhang, C. H., and G. W. Huang. 2019. "Xitonglun, Xi Tong Gongneng Yuyanxue Yu Shengtai Yuyanxue [Systems Theory, Systemic Functional Linguistics and Ecolinguistics]." Foreign Languages in China 5: 43-50.

Zhang, R. J. 2018. “Xi Tong Gongneng Yuyanxue Shijiao Xia Huayu Shengtaixing Fenxi Moshi Goujian [A Framework for Eco-oriented Discourse Analysis from the Perspective of Systemic Functional Linguistics]." Doctoral Dissertation, Beijing: University of Science and Technology Beijing.

Zhang, R. J., and W. He. 2018. "Shengtai Yuyanxue Shijiao Xia De Renji Yiyi Xitong [Interpersonal Meaning System Viewed from an Ecolinguistic Perspective]." Foreign Languages and Their Teaching 2: 99-108.

Zhang, R. J., and W. He. Forthcoming. "Ecolinguistics and Ecosophy: For a Harmonious Relationship between People and Place through the Intermediate Medium of Language." Linguistics and the Human Sciences.

Zhu, Y. S., and S. Q. Yan. 2001. Xitong Gongneng Yuyanxue Duowei Sikao [Reflections on Systemic Functional Linguistics]. Shanghai: Shanghai Foreign Language Education Press. 